\title{
Effect of a Herbal-Leucine mix on the IL-1 $\beta$ - induced cartilage degradation and inflammatory gene expression in human chondrocytes
}

\author{
Nahid Akhtar ${ }^{1}$, Mark JS Miller ${ }^{2}$ and Tariq M Haqqi ${ }^{*}$
}

\begin{abstract}
Background: Conventional treatments for the articular diseases are often effective for symptom relief, but can also cause significant side effects and do not slow the progression of the disease. Several natural substances have been shown to be effective at relieving the symptoms of osteoarthritis $(\mathrm{OA})$, and preliminary evidence suggests that some of these compounds may exert a favorable influence on the course of the disease. The objective of this study was to investigate the anti-inflammatory/chondroprotective potential of a Herbal and amino acid mixture containing extract of the Uncaria tomentosa, Boswellia spp., Lepidium meyenii and L-Leucine on the IL-1 $\beta$-induced production of nitric oxide (NO), glycosaminoglycan (GAG), matrix metalloproteinases (MMPs), aggrecan (ACAN) and type II collagen (COL2A1) in human OA chondrocytes and OA cartilage explants.
\end{abstract}

Methods: Primary OA chondrocytes or OA cartilage explants were pretreated with Herbal-Leucine mixture (HLM, 1$10 \mu \mathrm{g} / \mathrm{ml})$ and then stimulated with $\mathrm{IL}-1 \beta(5 \mathrm{ng} / \mathrm{ml})$. Effect of HLM on IL-1 $\beta$-induced gene expression of iNOS, MMP-9, MMP-13, ACAN and COL2A1 was verified by real time-PCR. Estimation of NO and GAG release in culture supernatant was done using commercially available kits.

Results: HLM tested in these in vitro studies was found to be an effective anti-inflammatory agent, as evidenced by strong inhibition of iNOS, MMP-9 and MMP-13 expression and NO production in IL-1 $\beta$-stimulated OA chondrocytes $(p<0.05)$. Supporting these gene expression results, IL-1 $\beta$-induced cartilage matrix breakdown, as evidenced by GAG release from cartilage explants, was also significantly blocked $(p<0.05)$. Moreover, in the presence of herbal-Leucine mixture (HLM) up-regulation of ACAN and COL2A1 expression in IL-1 $\beta$-stimulated OA chondrocytes was also noted $(p<0.05)$. The inhibitory effects of HLM were mediated by inhibiting the activation of nuclear factor (NF)-kB in human OA chondrocytes in presence of IL-1 $\beta$.

Conclusion: Our data suggests that HLM could be chondroprotective and anti-inflammatory agent in arthritis, switching chondrocyte gene expression from catabolic direction towards anabolic and regenerative, and consequently this approach may be potentially useful as a new adjunct therapeutic/preventive agent for OA or injury recovery.

\section{Background}

Osteoarthritis (OA) is the most common form of joint disease that evolves from local inflammatory disease to a chronic process with variable degree of inflammation and degeneration of articular cartilage that ultimately results in exposure of underlying bone, pain and

\footnotetext{
* Correspondence: thaqqi@metrohealth.org

'Department of Medicine/Rheumatology, MetroHealth Medical Center, Case Western Reserve University, 2500 Metro Health Drive, Cleveland, Ohio 44109, USA

Full list of author information is available at the end of the article
}

disability [1]. The aggregating cartilage proteoglycan, aggrecan (ACAN), along with the type II collagen (COL2A1) provide the robust mechanical properties to the cartilage in a healthy joint. The progressive degeneration of articular cartilage involves depletion of ACAN and the deregulation of matrix components, such as proteoglycan and collagen [2]. Enzymatic cleavage by matrix metalloproteinases (MMPs) is thought to be involved in the destruction of articular cartilage, so the high expression of MMP-13/collagenase-3 and MMP-9/ gelatinase $\mathrm{B}$ detected in the pathologic synovium and

\section{Biomed Central}


cartilage samples is believed to contribute to OA pathogenesis $[3,4]$. IL-1 $\beta$ is implicated in the degeneration of articular cartilage due to its induction of proteoglycan loss and matrix degradation [5]. Elevated levels of IL-1 occur in the synovial fluid and cartilage tissue of patients with OA [6], implying a role in disease pathogenesis. IL-1 receptor antagonist, a natural competitor of IL-1, suppresses cartilage loss, further supporting the role of IL-1 in cartilage breakdown [7]. Both IL-1 and mechanical loading of cartilage increase nitric oxide (NO) production $[8,9]$ by up-regulating the expression of inducible nitric oxide synthase gene (iNOS). NOS inhibitors inhibit the progression of $\mathrm{OA}$ in the experimental animal models [10], and the joint pathology is significantly inhibited in the collagen-induced arthritis model in NOS deficient mice [11]. Recent exceptional growth in human exposure to natural herbs used as traditional medicine has lead to a resurgence of scientific interest in their biological effects. Use of traditional medicinal plants for the treatment of OA has gained popularity because they are purported to show clinical efficacy with minimal side effects compared to mainstream treatment. Additionally, medicinal plants are often cheaper, locally available and easily consumable.

The Boswellia spp., which is native to Ethiopia, Somalia, India, and the Arabic peninsula, produce a gum resin that is known as olibanum (frankincense). The resin of Boswellia carteri and Boswellia serrata has been used for the treatment of rheumatoid arthritis and other inflammatory diseases in the traditional medicine system in many countries $[12,13]$. Besides their renowned antiinflammatory activity, Boswellic acids have been extensively investigated with respect to their chemopreventive effects $[14,15]$.

Lepidium meyenii (Maca) is an Andean plant of the Brassica (mustard) family. Preparations from maca root have been reported to be antioxidant [16,17] and improve sexual function [18]. We recently observed that Maca had chondroprotective properties in human cartilage [19]. This action was mediated in part through an up-regulation of gene expression of the anabolic growth factor IGF-1 even in the presence of the inflammatory cytokine IL-1. This effect on preventing cartilage breakdown and maintain balance of genetic resources governing catabolism and anabolism in human cartilage was enhanced when maca was combined with another South American medicinal plant Cat's claw (Uncaria guianensis). Follow up clinical studies in subjects with osteoarthritis of the knee indicated that this combination of cat's claw and maca was effective in alleviating arthritis symptoms in $92 \%$ of subjects [20]. Cat's claw is an Amazonian vine whose bark is used to make a decoction that has traditional use in managing inflammation, including joint health. This action has been supported by clinical studies in osteoarthritis [21] and attributed to its powerful antioxidant actions and its ability to inhibit the transcriptional factor NF-kB [17,22,23].

Leucine is a branch-chained amino acid that serves not only as a substrate for protein synthesis, but also as a nutrient signal to stimulate protein synthesis. The stimulation of protein synthesis achieved by Leucine supplementation occurs by the activation of translation initiation factors through the mTOR signaling pathway $[24,25]$. Reports state that Leucine supplementation can be used as an adjunct in the nutritional management for full protein delivery [26]. Joint health can be influenced by the supporting musculature and so approaches that enhance muscle mass and performance (nutritional and exercise) can be helpful in maintaining optimal joint health. However, to our knowledge little is known about the effects of Leucine on human chondrocytes.

The reason for using herbs in combination is that herbs have chemicals components which can bring strong beneficial effects. This also helps body to manage potentially undesirable effects of anyone/each herb in combination/formulation plays in a curative or pacifying role. It is therefore preferable to use herbal combination instead of depending on a single herb. However, the effect of Herbal-Leucine mixture (HLM) used in this study (contains three natural products and an amino acid: Uncaria tomentosa, Boswellia spp., Lepidium meyenii and L-Leucine) has not been studied in OA chondrocytes in relation to its chondroprotective/antiinflammatory potential. We therefore studied the effect of HLM on the expression of key molecules believed to be involved in OA pathogenesis such as NO, COL2A1, ACAN, glycosaminoglycans (GAGs) and MMPs in human OA chondrocytes and cartilage explants, stimulated with IL-1 $\beta$. We also investigated the effect of HLM on the activation of NF-kB in chondrocytes, which is a master transcription factor involved in upregulation of many of these inflammatory genes during OA pathogenesis.

\section{Methods}

\section{Cell isolation and human chondrocytes culture}

The protocol was approved and permission to use discarded and de-identified human tissue was obtained from the Institutional Review Board, MetroHealth Medical Centre (IRB09-01330), prior to the initiation of the studies. These studies were approved as "exempt" and that no informed consent was required. OA was diagnosed according to the American College of Rheumatology criteria [27,28]. Human chondrocytes were prepared by enzymatic digestion of cartilage obtained from nine osteoarthritis (OA) patients (mean age, $60.6 \pm 4.7$ years) who underwent knee arthroplasty at the MetroHealth Medical Centre, Cleveland, $\mathrm{OH}$. 
Specimens that included the full thickness cartilage and subchondral bone were washed with sterile PBS and the macroscopic cartilage degeneration was determined by staining with India ink [29]. Portions of the cartilage with smooth articular surface were used to prepare chondrocytes by the pronase and collagenase enzymatic digestion (OA chondrocytes) as previously described $[30,31]$. Primary OA chondrocytes were plated at the seeding density of $1 \times 10^{6}$ cell $/ 35 \mathrm{~mm}$ dish and at $80 \%$ confluence were used for all the studies described here.

\section{Preparation of Herbal-Leucine mixture (HLM) and treatment of chondrocytes with IL-1 $\beta$}

Herbal-Leucine mixture (HLM) was prepared by mixing extracts of Uncaria tomentosa (Cats Claw), Boswellia spp., Lepidium meyenii (maca) and pharmaceutical grade L-Leucine (Ajinimoto USA Inc, Fort Lee, NJ). The final mixture is a commercial product called FlexSure, (Vital g-Netics, Quitman, TX) and the recommended dose contains $1000 \mathrm{mg}$ Lepidium meyenii, $300 \mathrm{mg}$ Uncaria tomentosa, $200 \mathrm{mg}$ Boswelia serrata, $700 \mathrm{mg} \mathrm{L-}$ Leucine. OA chondrocytes at $80 \%$ confluence were serum starved in DMEM starving medium for 12-16 h and were pretreated with the HLM $(1-10 \mu \mathrm{g} / \mathrm{ml})$ for $2 \mathrm{~h}$ and were then stimulated with IL-1 $\beta(5 \mathrm{ng} / \mathrm{ml}$ ) (R\&D system, St. Paul, MN) for 6 or 24 h. An inhibitor of nuclear factor-kB (NF-kB), MG132 $(100 \mu \mathrm{M})$ was used as a positive control to study the effect of HLM on MMP-9, MMP-13 production and NF-kB inhibition. OA chondrocytes cultured without IL-1 $\beta$ served as controls. Culture supernatants were used to estimate total nitric oxide production.

\section{Cell viability assay}

OA chondrocytes were treated with the HLM (1 and 5 $\mu \mathrm{g} / \mathrm{ml}$ ) for $24 \mathrm{~h}$ and the cytotoxic effect of the herbal mixture was evaluated by lactate dehydrogenase (LDH) activity using CytoTox96 ${ }^{\circledR}$ Non-Radioactive Cytotoxicity Assay kit (Promega, Madison, WI). LDH is a soluble cytosolic enzyme that is released into the culture medium following loss of membrane integrity resulting from either apoptosis or necrosis. LDH activity, therefore, can be used as an indicator of cell membrane integrity and serves as a general means to assess cytotoxicity resulting from chemical compounds or environmental toxic factors. Kit measures LDH activity present in the culture medium using a coupled two-step reaction. In the first step, $\mathrm{LDH}$ catalyzes the reduction of $\mathrm{NAD}^{+}$to NADH and $\mathrm{H}^{+}$by oxidation of lactate to pyruvate. In the second step of the reaction, diaphorase uses the newlyformed $\mathrm{NADH}$ and $\mathrm{H}^{+}$to catalyze the reduction of a tetrazolium salt (INT) to highly-colored formazan which absorbs strongly at $490 \mathrm{~nm}$.

\section{Nitrite assay}

The interaction of NO in a system is measured by the determination of total nitrate and nitrite concentrations in the samples. Chondrocytes were pretreated for $2 \mathrm{~h}$ with HLM (1 and $5 \mu \mathrm{g} / \mathrm{ml}$ ) and then stimulated or not stimulated with IL-1 $\beta(5 \mathrm{ng} / \mathrm{ml})$ for $24 \mathrm{~h}$. Total nitric oxide assay kit (Thermo Scientific, Rockford, IL) was used for the assessment effects of IL-1 $\beta$ induced nitric oxide production in culture supernatants. The kit uses the enzyme nitrate reductase to convert the nitrate to nitrite. Nitrite is then detected as a colored azo dye product the Griess reaction that absorbs visible light at 540 nm.

\section{Quantitative real-time-PCR (RT-PCR)}

Real time quantitative-PCR was used to quantify the mRNA expression of matrix metalloproteinase-9 (MMP9, assay ID Hs00234579), MMP-13 (assay ID Hs00233992), Aggrecan (ACAN, assay ID Hs00153936), Type-II collagen (COL2A1, assay ID 00264051), and inducble nitric oxide synthase (iNOS, assay ID Hs01075526) using TaqMan Gene expression assays (Applied Biosystems, Foster city, CA). Total RNA was isolated from OA chondrocytes by Trizol reagent (Invitrogen, Carlsbad, CA) according to the manufacturer's instruction. First-strand cDNA was synthesized using 500 ng of total RNA and the QuantiTect Reverse Transcription kit (Qiagen, Valencia, CA). Quantitative PCR was performed in $20 \mu \mathrm{l}$ reactions containing $2 \mu \mathrm{l}$ of 10 -times diluted RT product, $10 \mu \mathrm{l}$ of $2 \mathrm{X}$ TaqMan Universal Master Mix (Applied Biosystems, Foster city, CA), $0.2 \mu \mathrm{M}$ TaqMan probe and $0.9 \mu \mathrm{M}$ forward and reverse primers. Reaction mixtures were incubated at $95^{\circ} \mathrm{C}$ for $10 \mathrm{~min}$, followed by 40 cycles of $95^{\circ} \mathrm{C}$ for $30 \mathrm{sec}$ and $60^{\circ} \mathrm{C}$ for 1 min. Expression of GAPDH was used as endogenous control. A threshold cycle $\left(C_{t}\right)$ was observed in exponential phase of amplification and quantification of relative expression levels was determined by $\Delta \Delta \mathrm{C}_{\mathrm{t}}$ method [32].

\section{Enzyme linked immune-sorbant assays (ELISA)}

Human chondrocytes were pretreated for $2 \mathrm{~h}$ with HLM $(1-10 \mu \mathrm{g} / \mathrm{ml})$ and then stimulated or not stimulated with IL-1 $\beta(5 \mathrm{ng} / \mathrm{ml})$ for $24 \mathrm{~h}$. The effect of IL- $1 \beta$ and/or HLM on the level of MMP-9 and MMP-13 secreted by chondrocytes in the culture medium was further confirmed by sandwich ELISAs (R\&D systems, Minneapolis, $\mathrm{MN}$ ) and all the assays were performed according to the manufacturer's instructions. Limit of detection for MMP-9 and MMP-13, was > $0.156 \mathrm{ng} / \mathrm{ml}$, and $7.7 \mathrm{pg} /$ $\mathrm{ml}$ respectively.

\section{Preparation and treatment of cartilage explants}

Full thickness cartilage slices were dissected from the unaffected cartilage using sterile scalpel blade (Feather 
Safety Razor Co. Osaka, Japan). Five cartilage pieces $(26.7 \mathrm{mg} \pm 1.3)$ were transferred to each well of a 24well, flat bottom plate (Falcon, NJ, USA) containing Dulbecco's modified Eagle's medium (DMEM) supplemented with antibiotics and $10 \%$ fetal bovine serum (FBS). After $24 \mathrm{~h}$ cultures, the medium was changed to starving medium (DMEM) and explants were starved for 12-16 h. The cartilage explants were treated with IL-1 $\beta$ alone or with the HLM ( 1 and $5 \mu \mathrm{g} / \mathrm{ml}$ ) or HLM alone for 7 days with the replacement of reagents every two days without medium change. Culture supernatants were used for determination of GAG release.

\section{Determination of glycosaminoglycans (GAGs)}

Level of sulfated GAGs released in the medium was measured by a metachromatic dye 1, 9-dimethylmethylene blue (DMMB) using proteoglycan detection kit (Astarte Biologics, WA). Briefly, $100 \mu \mathrm{l}$ of DMMB reagent was added to $100 \mu \mathrm{l}$ of culture supernatant. The GAG-dye complex results in absorption spectrum shift, which can be measured at $525 \mathrm{~nm}$. Values were derived from standard curve using different concentrations of chondroitin sulfate and the results are expressed as microgram GAG/gram of cartilage.

\section{Transient transfection and luciferase activity assay}

To study the effect of HLM on the IL-1 $\beta$-induced activation of NF-kB, human chondrocytes were transiently transfected with p-NF-kB-Luc reporter plasmid (Agilent Technologies, Santa Clara, CA). Briefly, OA chondrocytes were seeded at $1 \times 10^{6} /$ well in 6 well plates and were transfected with $\mathrm{p}-\mathrm{NF}-\mathrm{kB}$-Luc reporter plasmid using Lipofectamine reagent (Invitrogen, Carlsbad, CA) according to the instruction of the manufacturer. Transfected cells were pretreated with HLM (1-10 $\mu \mathrm{g} / \mathrm{ml})$ and/or stimulated with IL-1 $\beta$ for $24 \mathrm{~h}$. Cells were washed with icecold PBS, lysed using passive lysis buffer and the luciferase activity was determined using a commercially available kit according to the instructions of the manufacturer (Luciferase assay kit, Promega, Madison, WI).

\section{Statistical analysis}

All experiments were performed three times using independent samples. Values shown are mean \pm SE unless stated otherwise. Comparisons were performed using Origin 8.1 software package (one paired two tailed $t$-test with one way ANOVA and Tukey's post-hoc analysis) and $p<0.05$ was considered significant.

\section{Results}

Effects of Herbal-Lucine mixture (HLM) on the chondrocyte viability

LDH cytotoxicity assay showed that the HLM used did not reduce the chondrocytes viability significantly ( $p$ >
0.05). Ninety-two percent of chondrocytes treated with the HLM up to $5 \mu \mathrm{g} / \mathrm{ml}$ for $24 \mathrm{~h}$ were found to be viable (Figure 1).

Inhibition of inducible nitric oxide synthase (iNOS) and nitric oxide (NO) production by the Herbal-Leucine mixture in IL-1 $\beta$-stimulated human chondrocytes The effect of the HLM on IL-1 $\beta$-induced iNOS expression and NO production is shown in Figure 2A and $2 \mathrm{~B}$. Human OA chondrocytes were pretreated with HLM (1 and $5 \mu \mathrm{g} / \mathrm{ml}$ ) for $2 \mathrm{~h}$ and then stimulated or not stimulated with IL-1 $\beta$ (5 ng/ml) for $24 \mathrm{~h}$. Stimulation with IL-1 $\beta$ significantly increased the expression of iNOS (1740-fold; $\mathrm{p}<0.05$ ) and production of NO (4-fold; $\mathrm{p}<$ 0.05) respectively, compared to un-stimulated control. Importantly, cytokine-stimulated increase in iNOS mRNA levels was significantly inhibited (92\%; $\mathrm{p}<0.05$ ) by the pretreatment of OA chondrocytes with HLM (5 $\mu \mathrm{g} / \mathrm{ml}$ ) compared to IL-1 $\beta$-stimulated OA chondrocytes. Similarly, there was a significant down regulation in $\mathrm{NO}$ production (50\% and 52\%; $\mathrm{p}<0.05$ ) in IL-1 $\beta$-stimulated OA chondrocytes cultures that were pretreated with the $\mathrm{HLM}$ at 1 and $5 \mu \mathrm{g} / \mathrm{ml}$, respectively.

Down-regulation of IL-1 $\beta$-induced MMP-9 and MMP-13 mRNA and protein expression in human chondrocytes Next we investigated the impact of treatment with HLM on the IL-1 $\beta$-induced MMP-9 and MMP-13 mRNA and protein expression in human $\mathrm{OA}$ chondrocytes. As shown in Figure $3 \mathrm{~A}$ and $3 \mathrm{~B}$, IL-1 $\beta$-stimulation of human OA chondrocytes resulted in significant up-regulation of MMP-9 (14-fold) and MMP-13 (71-fold) mRNA expression $(p<0.05)$. The treatment of

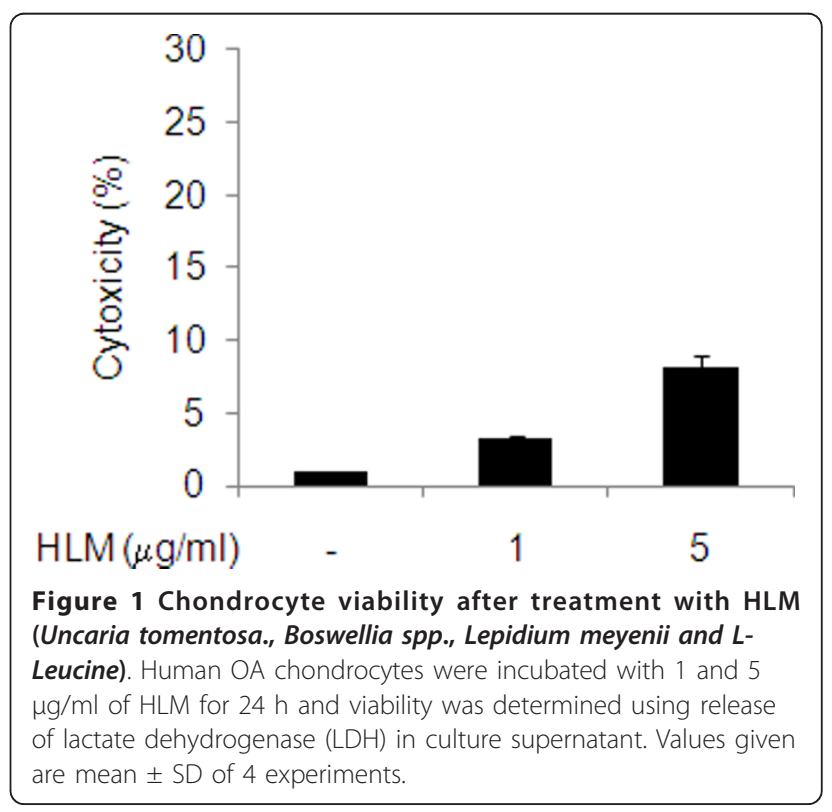



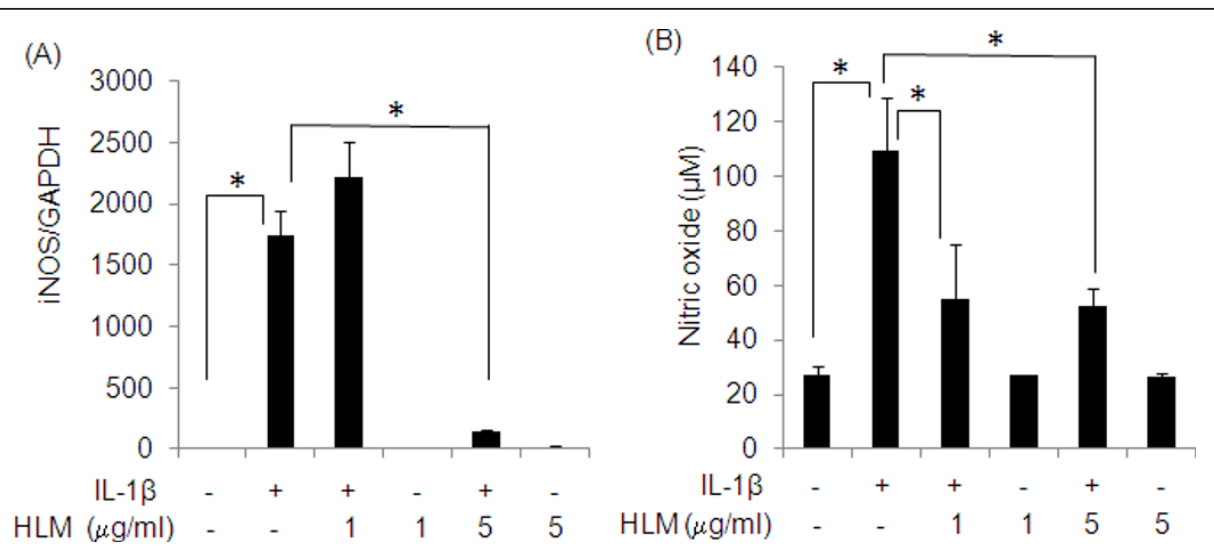

Figure 2 Effect of HLM (Uncaria tomentosa., Boswellia spp., Lepidium meyenii and L-Leucine) on the IL-1 $\beta$-induced gene expression of inducible nitric oxide synthase (iNOS) (A) and on the production of nitric oxide (NO) (B) in human OA chondrocytes. Chondrocytes were pretreated for $2 \mathrm{~h}$ with $\mathrm{HLM}(1-5 \mu \mathrm{g} / \mathrm{ml})$ and then stimulated or not stimulated with $\mathrm{IL}-1 \beta(5 \mathrm{ng} / \mathrm{ml})$ for $24 \mathrm{~h}$. Relative gene expression of iNOS was determined by Real-time PCR using GAPDH as endogenous control and compared with un-stimulated control. Corresponding culture supernatants were analyzed for total NO levels. Values represent Mean \pm SE of three different experiments run in duplicate. ${ }^{*} p<0.05$.

chondrocytes with the HLM (1 and $5 \mu \mathrm{g} / \mathrm{ml})$ showed 84-89\% decrease in the level of MMP-9 mRNA expression $(\mathrm{p}<0.05)$, compared to OA chondrocytes not treated with the HLM but were stimulated with IL-1 $\beta$ alone. To determine whether this inhibition of gene expression also influenced the MMP-9 protein production, culture supernatants were assayed for MMP-9 protein using a sandwich ELISA. A significant increase in secreted MMP-9 in the culture supernatant (11.7-fold) was found when OA chondrocytes were stimulated with
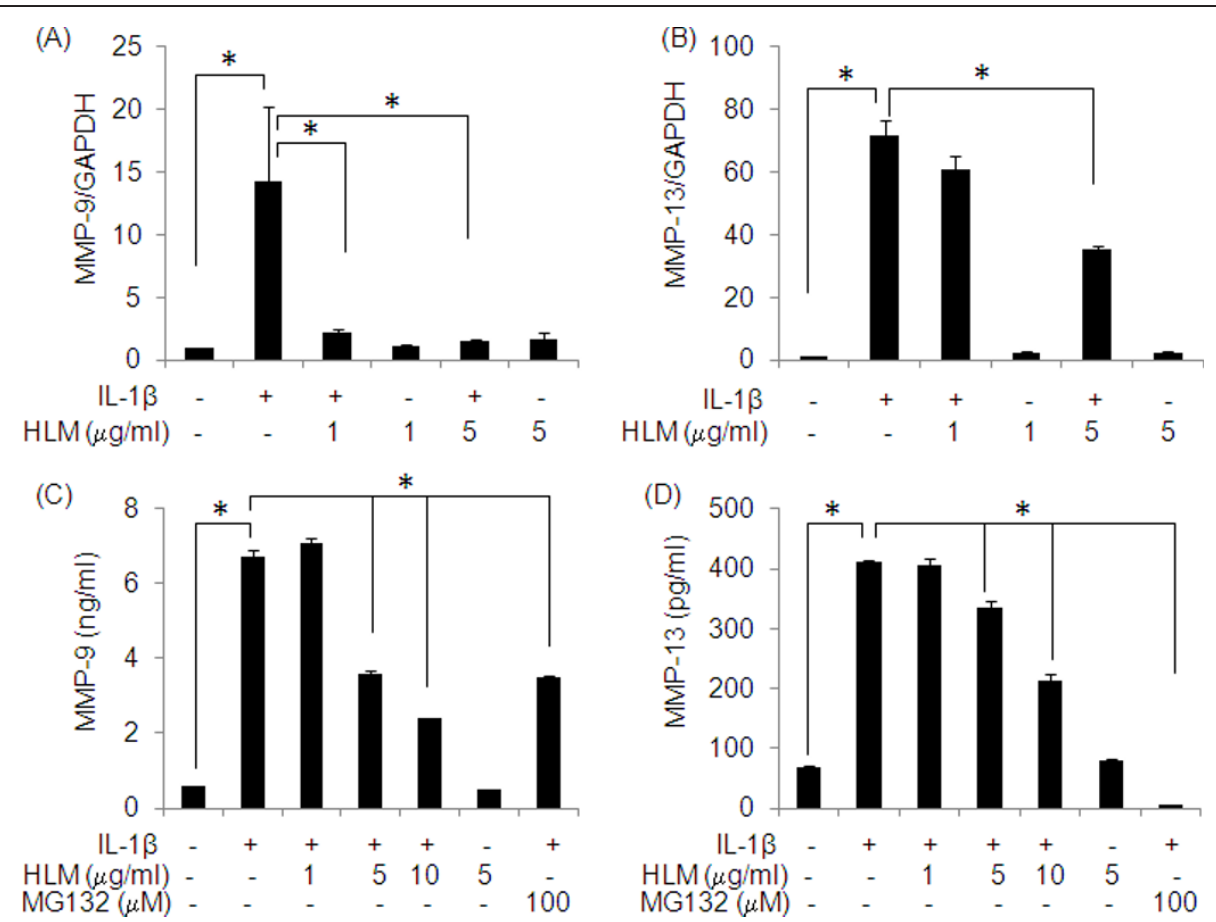

Figure 3 Effect of HLM (Uncaria tomentosa., Boswellia spp., Lepidium meyenii and L-Leucine) on the IL-1 $\beta$-induced expression of MMP-9 and MMP-13 in IL-1 $\beta$-stimulated OA chondrocytes. Chondrocytes were pretreated for $2 \mathrm{~h}$ with HLM $(1-10 \mu \mathrm{g} / \mathrm{ml})$ and then stimulated or not stimulated with IL-1 $\beta(5 \mathrm{ng} / \mathrm{ml})$ for $6 \mathrm{~h}$ for MMP-9 mRNA (A) and $24 \mathrm{~h}$ for MMP-13 mRNA(B). mRNA expression was analyzed by Real time-PCR. Relative gene expression was normalized to GAPDH and compared with un-stimulated control. Levels of MMP-9 (C) and MMP-13 (D) in culture supernatants were quantified by sandwich ELISA at $24 \mathrm{~h}$. Value represents Mean \pm SD of three different experiments runs in duplicate. ${ }^{*} p<$ 0.05 . 
IL-1 $\beta$ (Figure 3C; $\mathrm{p}<0.05$ ). However, pretreatment of chondrocytes with HLM significantly inhibited the MMP-9 production in IL- $1 \beta$-stimulated OA chondrocytes $(64 \%$, Figure $3 C ; \mathrm{p}<0.05)$. This inhibition in MMP-9 production was also noted when chondrocytes were pre-treated with MG132, a known NF-kB inhibitor, which inhibited the MMP-9 production by $47 \%$ (Figure $3 \mathrm{C} ; \mathrm{p}<0.05)$. Also pretreatment with HLM inhibited the IL-1 $\beta$-induced MMP-13 mRNA expression by $51 \%$ at $5 \mu \mathrm{g} / \mathrm{ml}$ (Figure 3B; $\mathrm{p}<0.05$ ). OA chondrocytes stimulated with IL-1 $\beta$ alone showed $504 \%$ increase in MMP-13 protein production, which was dose dependently inhibited (upto 49\%) by HLM (Figure 3D; p < 0.05). Interestingly, MG132 pretreatment also inhibited 99\% of MMP-13 production in OA chondrocytes.

\section{Effect of Herbal-Leucine mixture on IL-1 $\beta$-induced inhibition of ACAN and COL2A1 mRNA expression in human chondrocytes}

We explored if the HLM affected the ACAN and COL2A1 gene expression in chondrocytes stimulated with IL-1 $\beta$ or not stimulated but treated with HLM alone (Figure 4A and 4B). HLM alone treatment produced a significant increase in ACAN (50\%) and COL2A1 (63\%) mRNA expression at $5 \mu \mathrm{g} / \mathrm{ml}$ concentration in OA chondrocyte compared to un-stimulated control chondrocytes $(\mathrm{p}<0.05)$. IL-1 $\beta$-stimulation resulted in significant down regulation of ACAN (2.5-fold) and COL2A1 (5-fold) expression in OA chondrocytes. However, pretreatment of HLM (1 and $5 \mu \mathrm{g} / \mathrm{ml})$ significantly inhibited the IL-1 $\beta$ mediated down regulation of ACAN (49\%; p < 0.05) and COL2A1 (56-62\%; p < 0.05), compared to IL-1 $\beta$ alone stimulated OA chondrocytes.

\section{Inhibition of IL-1 $\beta$-induced cartilage matrix degradation}

The effect of HLM on the IL- $1 \beta$-induced cartilage matrix degradation is shown in Figure 5. Treatment

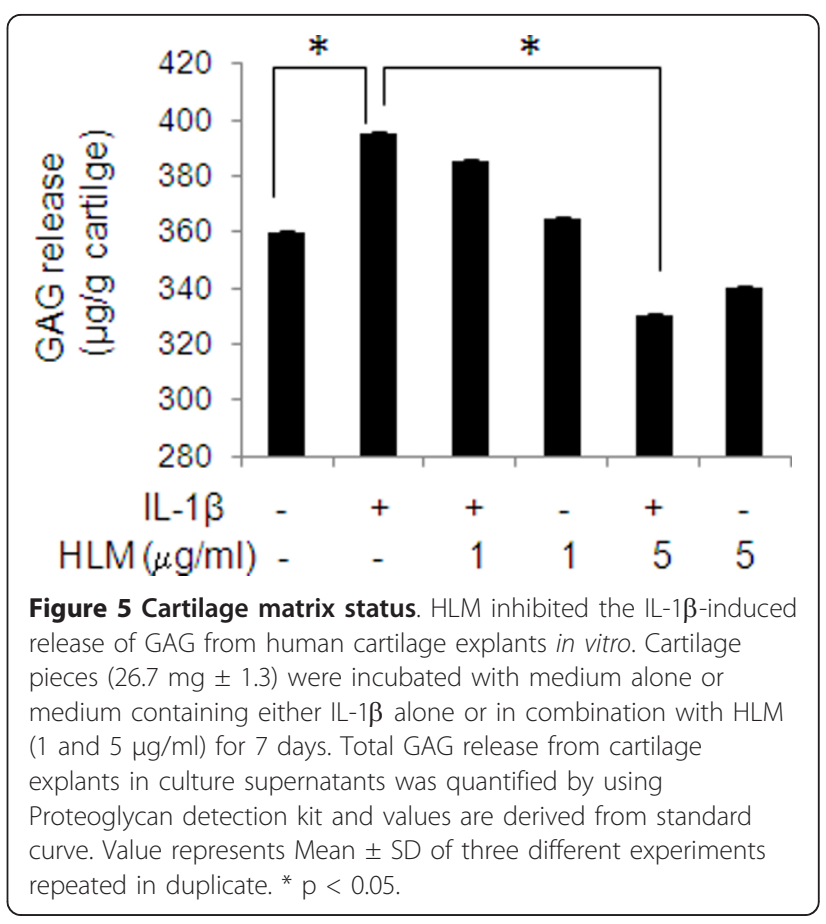

with IL-1 $\beta$-induced cartilage matrix degradation was increased by $9 \%$ in culture medium from cartilage explants, compared to un-stimulated control cartilage explants (Figure 5). However, the IL-1 $\beta$-induced release of GAG was significantly inhibited by the HLM (16\%; p $<0.05)$, compared to IL-1 $\beta$-stimulated OA cartilage explants. These results provide support that HLM may to be an effective agent for blocking the IL-1 $\beta$-induced release of GAGs from human cartilage, at least in vitro.

\section{Effect of HLM on NF-kB activation}

To determine directly whether HLM inhibit activation of NF-kB in IL-1 $\beta$-stimulated OA chondrocytes, we
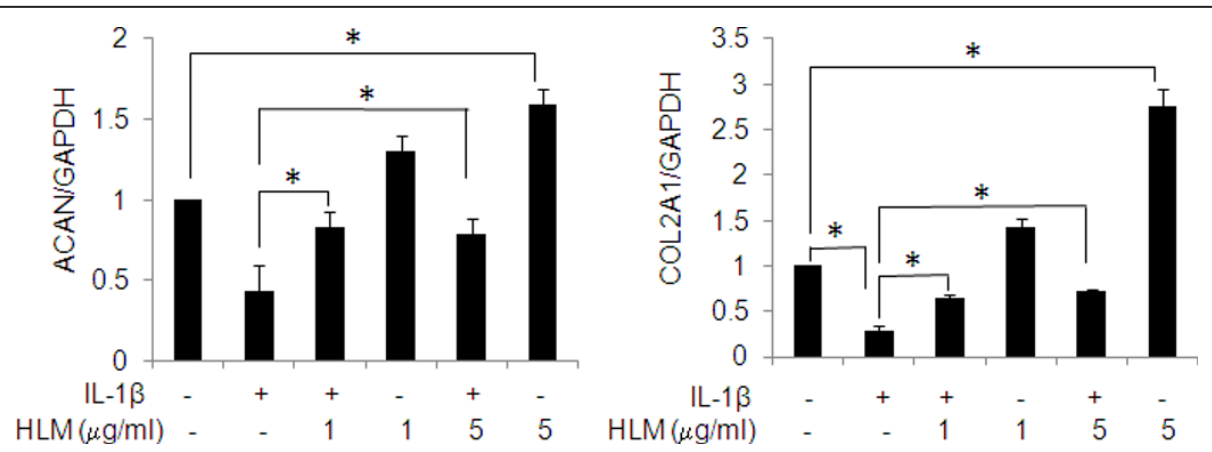

Figure 4 Effect of HLM (Uncaria tomentosa., Boswellia spp., Lepidium meyenii and L-Leucine) on the IL-1 $\beta$-induced gene expression of ACAN and COL2A 1 in IL-1 $\beta$-stimulated OA chondrocytes. Chondrocytes were pretreated for $2 \mathrm{~h}$ with $\mathrm{HLM}(1 \mathrm{and} 5 \mu \mathrm{g} / \mathrm{ml})$ and then stimulated or not stimulated with IL-1 $3(5 \mathrm{ng} / \mathrm{ml})$ for $24 \mathrm{~h}$, expression of ACAN (A) and COL2A1 (B) was analyzed by Real time-PCR. Relative gene expression was normalized to GAPDH and compared with un-stimulated control. Value represents Mean \pm SD of three different experiments run in duplicate. ${ }^{*} p<0.05$. 
used NF-kB-dependent gene reporter assay. OA chondrocytes were transiently transfected with pNF-kB-Luc reporter plasmid and then stimulated with IL-1 $\beta$. Stimulation of chondrocytes with IL- $1 \beta$ resulted in robust luciferase activity (Figure 6; $\mathrm{p}<0.05$ ). Interestingly, this luciferase activity was significantly reduced in OA chondrocytes treated with HLM prior to stimulation with IL$1 \beta$ (Figure 6; $\mathrm{p}<0.05$ ). Similar inhibition of luciferase activity was observed when chondrocytes were pretreated with MG132. Taken together these data indicate that HLM was a potent suppressor of NF-kB activity in OA chondrocytes.

\section{Discussion}

Osteoarthritis $(\mathrm{OA})$ is a heterogeneous, complex joint pathology of unknown etiology. Apart from the surgical measures, treatment of OA has generally been aimed to alleviating major complaints, such as pain, swelling, and muscle tightness and thus resulting in improved mobility [33]. Current treatment options include Non-steroidal Anti-Inflammatory Drugs (NSAIDs) including cyclooxygenase-2 (COX-2) inhibitors (rofecoxib) and others for pain relief but fail to block the progression of the disease [34]. Unfortunately, these agents are also associated with gastrointestinal, cardiovascular and other risks and do not abrogate the loss of cartilage matrix $[33,34]$. Nutraceuticals derived from herbs, spices and medicinal plants have long been used in the traditional medicine system of many nations including India and China, and have been shown to be effective as non-steroidal anti-inflammatory drugs at relieving the symptoms of OA, and preliminary evidence suggests that some of

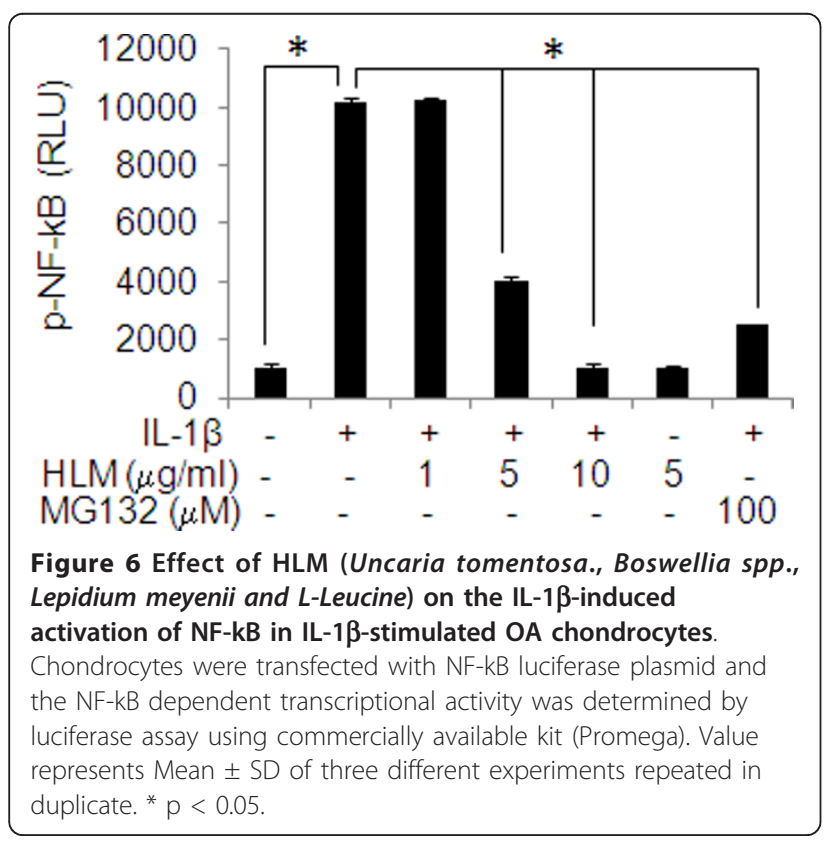

these compounds may exert a favorable influence on the course of the disease. In this study, we investigated the anti-inflammatory/chondroprotective potential of a Herbal-Leucine mixture (HLM) of four natural products: Uncaria tomentosa., Boswellia spp., Lepidium meyenii and L-Leucine on the production of key molecules released during chronic inflammatory events such as nitric oxide (NO), glycosaminoglycan (GAG), matrix metalloproteinases (MMPs), aggracan (ACAN) and type II collagen (COL2A1) by human chondrocytes and cartilage in the presence of IL-1 $\beta$. We have also studied the effect of HLM on the IL-1 $\beta$-induced NF-kB activation in these cells.

Uncaria has been found to inhibit lipopolysaccharide (LPS)-induced iNOS gene expression, nitrate formation, cell death, $\mathrm{PGE}_{2}$ and TNF $\alpha$ production and the activation of NF-kB $[23,35]$. Both species of Uncaria ( $U$. tomentosa and $U$. guianensis) were reported to be a strong free radical scavenger $[17,22]$. The available animal toxicological data did not indicate any severe toxicity by the oral intake of Uncaria [21,36]. Additionally, recent article supports the use of Uncaria spp. alone or in combination with other medicinal herbs for OA management $[20,37]$.

A randomized clinical trial of multiplant Ayurvedic drugs containing Boswellia Serrata as one of the component demonstrated the potential efficacy and safety in the symptomatic treatment of knee OA over 32 weeks of therapy [38]. Another trial of a herbomineral formulation containing Boswellia serrata as one of the components also showed significant reduction in severity of pain and disability score [39]. Further, Boswellic acids have been reported as inhibitors of 5-lipoxygenase, the key enzyme for leukotriene biosynthesis in inflammatory disorders $[40,41]$ and human leukocyte elastase [12]. Thus its use may be beneficial in inhibiting the severity of OA.

Although, the Lepidium meyenii root preparations have been reported to improve sexual function [18] and an antioxidant status [16] but, the role of Lepidium meyenii alone in OA management has not been investigated as yet. However, we noted that Lepidium meyenii had chondroprotective effects in human cartilage explants in a similar experimental protocol as this report [19] and as a component of an effective approach to the management of OA when administered in combination with Uncaria guianensis [20]. LLeucine has clinical support for its benefits in exercise and sports performance, which indirectly can improve joint health or delay progressive nature of osteoarthritis $[42,43]$. However, a direct action of L-Leucine on arthritic processes is not supported in the literature. Based on the results of this study it may be worthy of future investigation. 
Our results on HLM cytotoxicity shows that HLM had no significant effect on the chondrocytes viability at the concentrations used in $24 \mathrm{~h}$ cultures. Also, the effect of HLM on IL-1 $\beta$-induced NO production are interesting as inhibition of $\mathrm{NO}$ has been associated with the reduced pain, inflammation, proteoglycan loss in human OA patients and in animal models of arthritis $[10,11,44]$. Importantly, our results showed that HLM significantly inhibited the iNOS expression and NO production in IL-1 $\beta$-stimulated OA chondrocytes.

The MMPs are a family of 23 enzymes in humans which facilitate ECM turnover and breakdown under normal and disease conditions [3]. Pro-inflammatory cytokine IL-1 $\beta$-induced MMP-13 production by chondrocyte is the foremost collagenase in OA pathogenesis. Several other members including MMP-9 have been localized to cartilage or synovium in the arthritis patients [3]. Screening of MMPs specific inhibitors has gained attention recently but due to their monomodal nature, lack of specificity and greater side effects there is a need to develop therapeutic strategies focusing on prophylactic agents [45].

Our study showed that HLM can potently down regulate the IL-1 $\beta$ mediated induction of MMP-13 and MMP-9 mRNA and protein expression in human OA chondrocytes in vitro. It is important to note that cartilage explants reflect the cellular responses of only one cell type, the chondrocyte, as cartilage is a vascular and comprised of chondrocytes and matrix only. Thus, our results suggest that HLM may diminish MMP-mediated degeneration of cartilage in OA through its effects on human chondrocytes. A recent study has shown that Aflapin a novel synergistic composition derived from Boswellia serrata, inhibit MMP-3 in a controlled clinical study [46]. Boswellia frereana extracts has also been reported to inhibit IL-1 $\beta$ and oncostatin $M$ induced MMP-9 and MMP-13 expression in cartilage explants cultures [47]. Similarly, Uncaria sinensis has also shown significant inhibition against MMP-2 and -9 activities in vascular smooth muscle cells [48]. Thus the observed beneficial anti-inflammatory effects of HLM may be due to Boswellia and Uncaria combination present in HLM.

A consequence of $\mathrm{OA}$ is the pro-inflammatory cytokine IL- $1 \beta$-induced down-regulation of cartilage anabolic factors such as ACAN, proteoglycan and COL2A1 [6]. Our results also showed that HLM has the potential to inhibit IL-1 $\beta$-induced GAG release from cartilage explants. Beside this, HLM alone or in the presence of IL- $1 \beta$ has up-regulated the COL2A1 and ACAN expression in OA chondrocytes. Aggrecan is degraded predominantly by aggrecanases and MMPs [3]. The observed inhibition of GAG release by HLM may possibly be due to MMPs and NO inhibition by HLM. Moreover, induction of COL2A1 and ACAN expression by HLM suggests that this could intercept the process of cartilage degeneration during the pathogenesis of OA. Whether it can extend these benefits to building the mass of cartilage matrix beyond existing downsized levels needs further investigations.

The transcription factor NF- $k B$ is a redox-sensitive transcription factor that regulates the expression of genes involved in osteoarthritis [49]. Because the suppression of NF-kB has been linked with anti-inflammatory activity, we postulated that HLM mediated inhibitory effects on the inflammatory genes expression discovered in this study could be at least in part through the suppression of NF-kB activity. The data indicated that HLM attenuates the IL- $1 \beta$-induced activation of NF-kB in OA chondrocytes.

\section{Conclusions}

In conclusion, we demonstrated that HLM inhibits the pro-inflammatory cytokine IL- $1 \beta$-stimulated expression of major proteases (MMP-9 and MMP13), NO and GAG release associated with cartilage degradation. We also showed cartilage protective ability of HLM by upregulating cartilage anabolic factors like COL2A1 and ACAN in OA chondrocytes. This is achieved at least in part by inhibiting NF-kB activation in human OA chondrocytes in vitro. Thus, with this unique profile of actions HLM may prove to be a potentially attractive and new therapeutic/preventive agent for OA and assist in the recovery from cartilage based sports injuries.

\section{Acknowledgements}

This work was supported in part by grants from National Institute of Health/ National Centre for Complimentary and Alternative Medicine grant (RO1 AT003267; RO1-AT-005520, R21-AT504615) and funds from the MetroHealth Medical Centre. We also thank Dr. Brendan Patterson (Department of Orthopedics, MHMC) for providing human OA cartilage samples.

\section{Author details}

${ }^{1}$ Department of Medicine/Rheumatology, MetroHealth Medical Center, Case Western Reserve University, 2500 Metro Health Drive, Cleveland, Ohio 44109, USA. ${ }^{2}$ MJSM: 2801 Summit Avenue, Plano 75074, Texas, USA.

\section{Authors' contributions}

NA carried out the experimental work, collection, interpretation and manuscript drafting. MJSM helped with data interpretation and drafting of the manuscript. TMH conceived of the study, its design, coordinated, data interpretation and manuscript drafting. All authors have read and approved the final manuscript.

\section{Competing interests}

Product is "intended" to be commercial (Vital g-Netics, LLC) but is indeed not yet released for commercial purposes. This was an exploratory study for which the HLM was provided by Vital g-Netics. No other input or support was provided or sought from the company.

Received: 13 May 2011 Accepted: 19 August 2011 Published: 19 August 2011

\section{References}

1. Feldmann M: Pathogenesis of arthritis: recent research progress. Nature Immunol 2001, 2:771-773. 
2. Flugge $L A$, Miller-Deist $L A$, Petillo PA: Towards a molecular understanding of arthritis. Chem Biol 1999, 6(6):R157-R166.

3. Burrage PS, Mix KS, Brinckerhoff CE: Matrix metalloproteinases: role in arthritis. Front Biosci 2006, 11:529-543.

4. Takaishi H, Kimura T, Dalal S, Okada Y, D'Armiento J: Joint diseases and matrix metalloproteinases: a role for MMP-13. Curr Pharm Biotechnol 2008, 9(1):47-54.

5. Kobayashi M, Squires GR, Mousa A, Tanzer M, Zukor DJ, Antoniou J, Feige U, Poole AR: Role of interleukin-1 and tumor necrosis factor alpha in matrix degradation of human osteoarthritic cartilage. Arthritis Rheum 2005, 52(1):128-135.

6. Goldring SR, Goldring MB: The role of cytokines in cartilage matrix degeneration in osteoarthritis. Clin Orthop Relat Res 2004, 427:S27-36.

7. Pelletier JP, Caron JP, Evans C, Robbins PD, Georgescu HI, Jovanovic D: In vivo suppression of early experimental osteoarthritis by interleukin-1 receptor antagonist using gene therapy. Arthritis Rheum 1997, 40:1012-1019.

8. Stadler J, Stefanovic-Racic M, Billiar TR, Curran RD, McIntyre LA, Georgescu HI: Articular chondrocytes synthesize nitric oxide in response to cytokines and lipopolysaccharide. J Immunol 1991, 147:3915-3920.

9. Fermor B, Weinberg JB, Pisetsky DS, Misukonis MA, Banes AJ, Guilak F: The effects of static and intermittent compression on nitric oxide production in articular cartilage explants. J Orthop Res 2001, 19:729-737.

10. Pelletier JP, Jovanovic D, Fernandes JC, Manning P, Connor JR, Currie MG: Reduced progression of experimental osteoarthritis in vivo by selective inhibition of inducible nitric oxide synthase. Arthritis Rheum 1998, 41:1275-1286.

11. van den Berg WB, van de Loo F, Joosten LA, Arntz OJ: Animal models of arthritis in NOS2-deficient mice. Osteoarthritis Cartilage 1999, 7:413-415.

12. Safayhi H, Ammon HPT: Pharmakologische Aspecte von Weihrauch und Boswellias"auren. Pharmazeutisch Zeitung 1997, 142:3277-3280.

13. Chevrier MR, Ryan AE, Lee DY, Zhongze M, Wu-Yan Z, Via CS: Boswellia carterii extract inhibits TH1 cytokines and promotes TH2 cytokines in vitro. Clin Diagn Lab Immunol 2005, 12(5):575-580.

14. Glaser T, Winter S, Groscurth P, Safayhi H, Sailer ER, Ammon HP, Schabet M: Boswellic acids and malignant glioma: induction of apoptosis but no modulation of drug sensitivity. British J Cancer 1999, 80:756-765.

15. Zhao W, Entschladen F, Liu H, Niggemann B, Fang Q, Zenker KS, Han R: Boswellic acid acetate induced differentiation and apoptosis in highly metastatic melanoma and fibrosarcoma cells. Cancer Detection Prevention 2003, 27:67-75

16. Vecera R, Orolin J, Skottová N, Kazdová L, Oliyarnik O, Ulrichová J, Simánek V: The influence of maca (Lepidium meyenii) on antioxidant status, lipid and glucose metabolism in rat. Plant Foods Hum Nutr 2007, 62(2):59-63.

17. Sandoval M, Okuhama NN, Zhang X-J, Condezo LA, Lao J, Angeles FM: Anti-inflammatory and antioxidant activities of cat's claw (Uncaria tomentosa and Uncaria guianensis) are independent of their alkaloid content. Phytomedicine 2002, 9:325-337.

18. Shin BC, Lee MS, Yang EJ, Lim HS, Ernst E: Maca (L. meyenii) for improving sexual function: a systematic review. BMC Complement Altern Med 2010, 10:44

19. Miller MJ, Ahmed S, Bobrowski P, Haqqi TM: The chrondoprotective actions of a natural product are associated with the activation of IGF-1 production by human chondrocytes despite the presence of IL-1 beta. BMC Complement Altern Med 2006, 6:13.

20. Mehta K, Gala J, Bhasale S, Naik S, Modak M, Thakur H, Deo N, Miller MJ: Comparison of glucosamine sulfate and a polyherbal supplement for the relief of osteoarthritis of the knee: a randomized controlled trial [ISRCTN25438351]. BMC Complement Altern Med 2007, 7:34

21. Piscoya J, Rodriquez Z, Bustamante SA, Okuhama NN, Miller MJS, Sandoval M: Efficacy and safety of freeze-dried cat's claw in osteoarthritis of the knee: mechanisms of action of the species Uncaria guianensis. Inflammation Res 2001, 50:442-448.

22. Sandoval M, Chaarbonnett RM, Okuhama NN, Roberts J, Krenova Z, Trentacosti AM: Cat's claw inhibits TNFa production and scavenges free radicals: role in cytoprotection. Free Rad Biol Med 2000, 29(1):71-78.

23. Sandoval-Chacon M, Thompson JH, Zhang X-J, Liu X, Mannick EE, Sadowska-Krowicka H: Anti-inflammatory action of cat's claw: the role of NF-kB. Aliment Pharmacol Therapy 1998, 12:1279-1289.
24. Escobar J, Frank JW, Suryawan A, Nguyen HV, Kimball SR, Jefferson LS, Davis TA: Physiological rise in plasma leucine stimulates muscle protein synthesis in neonatal pigs by enhancing translation initiation factor activation. Am J Physiol Endocrinol Metab 2005, 288:E914-E921.

25. Kimball SR, Jefferson LS: Regulation of protein synthesis by branchedchain amino acids. Curr Opin Clin Nutr Metab Care 2001, 4:39-43.

26. Murgas TR, Suryawan A, Gazzaneo MC, Orellana RA, Frank JW, Nguyen HV, Fiorotto ML, El-Kadi S, Davis TA: Leucine supplementation of a lowprotein meal increases skeletal muscle and visceral tissue protein synthesis in neonatal pigs by stimulating mTOR-dependent translation initiation. J Nutr 2010, 140(12):2145-2152.

27. Altman R, Alarcón G, Appelrouth D, Bloch D, Borenstein D, Brandt K: The American College of Rheumatology criteria for the classification and reporting of osteoarthritis of the hip. Arthritis Rheum 1991, 34(5):505-514.

28. Altman R, Asch E, Bloch D, Bole G, Borenstein D, Brandt K: Development of criteria for the classification and reporting of osteoarthritis. Classification of osteoarthritis of the knee. Diagnostic and Therapeutic Criteria Committee of the American Rheumatism Association. Arthritis Rheum 1986, 29(8):1039-1049.

29. Armstrong CG, Mow VC: Variations in the intrinsic mechanical properties of human articular cartilage with age, degeneration and water content. J Bone Joint Surg 1982, 64(A):88-94.

30. Shukla M, Gupta K, Rasheed Z, Khan KA, Haqqi TM: Bioavailable constituents/metabolites of pomegranate (Punica granatum $\mathrm{L}$ ) preferentially inhibit COX2 activity ex vivo and IL-1ß-induced PGE2 production in human chondrocytes in vitro. J Inflamm (Lond) 2008, 5:9-18.

31. Singh R, Ahmed S, Islam N, Goldberg VM, Haqqi TM: Epigallocatechin-3 gallate inhibits interleukin-1beta-induced expression of nitric oxide synthase and production of nitric oxide in human chondrocytes: suppression of nuclear factor kappaB activation by degradation of the inhibitor of nuclear factor kappaB. Arthritis Rheum 2002, 46(8):2079-2086.

32. Pfaffl MW: A new mathematical model for relative quantification in realtime RT-PCR. Nucleic Acids Res 2001, 29(9):e45.

33. Palmieri B, Lodi D, Capone S: Osteoarthritis and degenerative joint disease: local treatment options update. Acta Biomed 2010, 81(2):94-100.

34. Singh R, Akhtar N, Haqqi TM: Green tea polyphenol epigallocatechin-3gallate: inflammation and arthritis. Life Sci 2010, 86(25-26):907-918.

35. Allen-Hall L, Arnason JT, Cano P, Lafrenie RM: Uncaria tomentosa acts as a potent TNF-alpha inhibitor through NF-kappaB. J Ethnopharmacol 2010, 127(3):685-693.

36. Valerio LG Jr, Gonzales GF: Toxicological aspects of the South American herbs cat's claw (Uncaria tomentosa) and Maca (Lepidium meyenii): a critical synopsis. Toxicol Rev 2005, 24(1):11-35.

37. Rosenbaum CC, O'Mathúna DP, Chavez M, Shields K: Antioxidants and antiinflammatory dietary supplements for osteoarthritis and rheumatoid arthritis. Altern Ther Health Med 2010, 16(2):32-40.

38. Chopra A, Lavin P, Patwardhan B, Chitre D: A 32-week randomized, placebo-controlled clinical evaluation of RA-11, an Ayurvedic drug, on osteoarthritis of the knees. J Clin Rheumatol 2004, 10(5):236-245.

39. Kulkarni RR, Patki PS, Jog VP, Gandage SG, Patwardhan B: Treatment of osteoarthritis with a herbomineral formulation: a double-blind, placebocontrolled, cross-over study. J Ethnopharmacol 1991, 33(1-2):91-95.

40. Safayhi H, Mack T, Sabieraj J, Anazodo MI, Subramanian LR, Ammon HP: Boswellic acids: novel, specific, nonredox inhibitors of 5-lipoxygenase. Pharmacol Exp Ther 1992, 261(3):1143-1146.

41. Gupta I, Parihar A, Malhotra P, Singh GB, Lüdtke R, Safayhi H, Ammon HP. Effects of Boswellia serrata gum resin in patients with ulcerative colitis. Eur J Med Res 1997, 2(1):37-43.

42. Crowe MJ, Weatherson JN, Bowden BF: Effects of dietary leucine supplementation on exercise performance. Eur J Appl Physiol 2006, 97(6):664-672

43. Walker TB, Smith J, Herrera M, Lebegue B, Pinchak A, Fischer J: The influence of 8 weeks of whey-protein and leucine supplementation on physical and cognitive performance. Int J Sport Nutr Exerc Metab 2010, 20(5):409-417.

44. Reddy SV, Wanchu A, Khullar M, Govindrajan S, Bambery P: Leflunomide reduces nitric oxide production in patients with active rheumatoid arthritis. Int Immunopharmacol 2005, 5(6):1085-1090.

45. Clutterbuck AL, Asplin KE, Harris P, Allaway D, Mobasheri A: Targeting matrix metalloproteinases in inflammatory conditions. Curr Drug Targets 2009, 10(12):1245-1254. 
46. Sengupta K, Krishnaraju AV, Vishal AA, Mishra A, Trimurtulu G, Sarma KV, Raychaudhuri SK, Raychaudhuri SP: Comparative efficacy and tolerability of 5-Loxin and AflapinAgainst osteoarthritis of the knee: a double blind, randomized, placebo controlled clinical study. Int J Med Sci 2010, 7(6):366-377.

47. Blain EJ, Ali AY, Duance VC: Boswellia frereana (frankincense) suppresses cytokine-induced matrix metalloproteinase expression and production of pro-inflammatory molecules in articular cartilage. Phytother Res 2010, 24(6):905-912.

48. Ha KT, Lee TK, Kwak KH, Kim JK, Kim DI, Choi DY, Kim CH: Inhibitory effect of Cho-Deung-San on human aortic smooth muscle cell migration induced by TNF-alpha through inhibition of matrix metalloproteinase-2 and -9 activity. Vascul Pharmacol 2004, 41(3):83-90.

49. Marcu KB, Otero M, Olivotto E, Borzi RM, Goldring MB: NF-kappaB signaling: multiple angles to target OA. Curr Drug Targets 2010, 11(5):599-613.

Pre-publication history

The pre-publication history for this paper can be accessed here: http://www.biomedcentral.com/1472-6882/11/66/prepub

doi:10.1186/1472-6882-11-66

Cite this article as: Akhtar et al: Effect of a Herbal-Leucine mix on the

IL-1 $\beta$-induced cartilage degradation and inflammatory gene expression

in human chondrocytes. BMC Complementary and Alternative Medicine

2011 11:66.

\section{Submit your next manuscript to BioMed Central} and take full advantage of:

- Convenient online submission

- Thorough peer review

- No space constraints or color figure charges

- Immediate publication on acceptance

- Inclusion in PubMed, CAS, Scopus and Google Scholar

- Research which is freely available for redistribution

Submit your manuscript at www.biomedcentral.com/submit 